\title{
EFEITO DA TELA ANTIGRANIZO EM ALGUMAS CARACTERÍSTICAS DOS FRUTOS DE MACIEIRA ${ }^{1}$
}

\author{
GABRIEL BERENHAUSER LEITE ${ }^{2}$, JOSÉ LUIZ PETRI ${ }^{2}$, MÁRCIA MONDARDO ${ }^{2}$
}

\begin{abstract}
RESUMO: A cobertura do pomar com telas de náilon é uma opção de combate ao granizo, principalmente em pequenas áreas. Durante cinco anos, avaliou-se o efeito do sombreamento provocado pela tela antigranizo, com níveis de sombreamento de $12 \%, 18 \%$ e $30 \%$, sobre os fatores de produção na macieira, cvs. Gala e Fuji. A coloração vermelha dos frutos foi a variável mais afetada pelo sombreamento, reduzindo-se até $14,2 \%$ da coloração na cv. Gala e 7,2\% na cv. Fuji. O sombreamento reduziu a incidência de "russeting" nos frutos, mas aumentou a incidência da mancha de glomerela. No último ano de avaliação, as plantas com cobertura de tela apresentaram uma redução de 19\% no número de gemas com flor, quando comparadas com as plantas sem cobertura.
\end{abstract}

Termos para indexação: Malus domestica, proteção a granizo, sombreamento.

\section{EFFECTS OF NET SHIELD AGAINST HAILSTORM ON FEATURE OF APPLES PRODUCTION AND FRUIT QUALITY}

\begin{abstract}
ABSTRAT: A net shield is a good option for protection of apple trees against hailstorm, especially for small orchards. The shading effects caused by net shield on production feature and fruit quality was evaluated for five years. Three types of net shield that caused $12 \%, 18 \%$ and $30 \%$ of shading were used on 'Gala' and 'Fuji' apple trees. Reduction of fruit red color was the main negative effect of shading. Fruit red color was reduced up to 14.2 $\%$ for 'Gala' and $7.2 \%$ for 'Fuji' when net shield was applied. The shading also reduced incidence of fruit with 'russeting' but increased incidence of 'glomerela' spot. Apple trees covered with the net for five years developed approximately $19 \%$ less bud flowers than uncovered trees.
\end{abstract}

Index terms: Malus domestica, hail protection, shading.

\section{INTRODUÇÃO}

O fenômeno de ocorrência de granizo na região meio-oeste de Santa Catarina é freqüente, apresentando uma média anual de 36 eventos, principalmente nos meses de primavera e verão, durante o ciclo vegetativo das principais fruteiras cultivadas nesta região.

O dano provocado pelo granizo é variável, dependendo do tamanho das pedras, densidade por área, duração, velocidade de queda, idade das plantas e época de ocorrência (MOTA, 1981). Em macieira, se o fruto for atingido logo após a floração, as frutas ficam deformadas, depreciando sua qualidade. Em frutos maiores, os danos por granizo resultam em lesões que favorecem a entrada de patógenos, impossibilitando, muitas vezes, sua comercialização. Quando em intensidade alta, o granizo pode comprometer produções futuras devido ao dano causado nos ramos e nas folhas das plantas, favorecendo o desenvolvimento de fungos que causam cancro nos ramos. Estima-se que as perdas anuais por granizo podem chegar a $20 \%$ da produção de maçãs no Sul do Brasil (ABPM, 1995). A Empresa Agrícola Fraiburgo S.A., em Fraiburgo, Santa Catarina, apresentou perdas de 9,0\%, 6,6\%, 1,0\% e 16,1\% dos frutos, nos ciclos 95/96, 97/98, 98/99 e 99/00, respectivamente, na fase de classificação, com dano de granizo, sendo esta ocorrência variável de ano para ano.

Na região de Fraiburgo, Santa Catarina, tentou-se controlar o granizo através do bombardeamento das nuvens com iodeto de prata lançado por foguetes estacionados em estações fixas e controlados por um radar meteorológico. Em anos de alta incidência de granizo, chegouse a lançar mais de 1.800 foguetes durante um ciclo. $O$ alto custo deste método e dúvidas na sua eficiência levaram os produtores a suspender a sua utilização.

Em substituição aos foguetes, o controle de granizo em grandes áreas é feito atualmente pelo método de queimadores de solo, utilizando o mesmo reagente dos foguetes, que é o iodeto de prata.

Uma das opções atualmente em teste para controle local do granizo é o uso de telas, que consiste na cobertura do pomar com telas de nylon. Esta técnica, apesar de só agora estar recebendo atenção no Brasil, não é nova. A primeira tentativa de proteção do granizo pelo uso de cobertura com tela plástica deu-se na Itália, em 1957 (Corino, 1980).

Nos últimos 40 anos, diversos sistemas de telas foram desenvolvidos em vários países, comprovando a eficiência deste tipo de controle sobre o granizo (Rosini e Vento, 1976; Ragazzini e Veronesi, 1980).
Como toda estrutura plástica, o uso de tela antigranizo pode vir a formar microclimas, modificando a resposta da planta. Como não temos, ainda, no Brasil, telas desenvolvidas especialmente para este fim, aproveitam-se as telas conhecidas como sombrites, que têm a função de reduzir a luminosidade, existindo no mercado telas com diversos níveis de sombreamento. O efeito da tela de proteção antigranizo limita a qualidade do produto final, pois modifica o microclima do ambiente (Corino, 1980).

A temperatura do ar no ambiente sobre proteção da tela fica $0,5^{\circ} \mathrm{C}$ a $1,5^{\circ} \mathrm{C}$ inferior ao ambiente sem proteção, enquanto a umidade do ar aumenta no ambiente protegido (Vento, 1982).

O presente trabalho tem por objetivo avaliar a proteção da tela sobre o dano de granizo nos frutos e o sombreamento provocado pela mesma, sobre a produção da macieira das cultivares Gala e Fuji.

\section{MATERIALEMÉTODOS}

O trabalho foi conduzido nos pomares da Empresa Pomifrai, em Fraiburgo-SC, com as cvs. Gala e Fuji durante 5 anos. Os tratamentos consistiram de níveis de sombreamento das telas de $12 \%, 18 \%$ e $30 \%$ para a cv. Gala e $12 \%$ e $18 \%$ para a cv. Fuji, mais o controle, sem tela. Em todos os níveis de sombreamento, utilizou-se tela de coloração preta.

Para cada nível de sombreamento, foram escolhidas 10 plantas ao acaso, além de mais 10 plantas sem cobertura. Em cada planta, foram previamente marcados dois ramos, um em cada lado, sendo colhidos todos os frutos para análise. As variáveis inicialmente analisadas foram: dano por granizo, crescimento dos ramos, crescimento dos frutos, porcentagem de coloração vermelha nos frutos, porcentagem de russeting, $\mathrm{pH}$, SST, firmeza da polpa, degradação do amido e teores de nutrientes em folhas e frutos e incidência de mancha de glomerela (Colletotricum sp.). A porcentagem de coloração vermelha dos frutos foi avaliada visualmente em uma amostragem de 100 frutos por planta. No último ano, foram avaliadas as variáveis formação de gemas floríferas, porcentagem de gemas com frutos e atividade das abelhas na época de floração. Medidas de temperatura do ar foram realizadas utilizando-se de termômetros de máxima e mínima.

As variáveis estudadas foram submetidas à análise de variância e as médias de tratamentos comparadas pelo teste de Duncan, a 5\% de probabilidade. 


\section{RESULTADOS E DISCUSSÃO}

A eficiência da tela no controle do dano de granizo pode ser comprovada no ciclo 96/97, único que apresentou ocorrência de granizo na área experimental durante o período vegetativo em que as plantas apresentaram frutos (Tabela 1). Todas as telas utilizadas apresentaram $100 \%$ de eficiência na proteção dos frutos aos danos por granizo.

TABELA 1 - Percentagem de frutos com dano de granizo na área experimental em 1997 - Fraiburgo-SC.

\begin{tabular}{ccc}
\hline Sombreamento & cv. Gala & cv. Fuji \\
\hline 0 & 45,9 & 19,4 \\
12 & 0,0 & 0,0 \\
18 & 0,0 & 0,0 \\
30 & 0,0 & --
\end{tabular}

Durante os cinco anos de avaliação, não foi observado, nas duas cultivares testadas, Gala e Fuji, efeito do sombreamento nas seguintes variáveis: crescimento do ramo e dos frutos, produção por planta, sólidos solúveis totais, acidez, $\mathrm{pH}$, firmeza e teores de amido nos frutos. Os teores de nutrientes foliares na polpa dos frutos também não foram influenciados pelo sombreamento. O crescimento dos ramos, embora não tenha diferenças significativas, mostrou uma tendência de maior crescimento nas plantas sob a tela, sendo mais acentuado na cv. Gala.

As temperaturas sob a tela antigranizo ficaram entre $1,0^{\circ} \mathrm{C}$ e 1,5 ${ }^{\circ} \mathrm{C}$ mais baixas do que nas áreas sem tela, medidas através de termômetros de máxima e mínima, no horário entre 10 e 14 horas.

A coloração vermelha do fruto foi a variável mais afetada pelo sombreamento, sendo também a que sofreu maior variação de ano para ano, em função das condições climáticas, pois, boa coloração do fruto depende da amplitude térmica entre as temperaturas diurnas e noturnas, que, quanto maior, melhor para a coloração dos frutos.

O uso da tela antigranizo provocou uma redução na coloração vermelha dos frutos entre 11,3 e 14,2\% na cv. Gala e entre 2,8 e 7,2\% na cv. Fuji. Em anos em que as condições climáticas não propiciaram uma boa coloração dos frutos, o efeito negativo da tela foi ampliado, como no ciclo 96/97, no caso da cv. Gala. A cv. Fuji respondeu exatamente ao contrário, havendo pouca variação na coloração dos frutos dentro e fora da tela (Tabela 2).

TABELA 2 - Porcentagem de coloração vermelha dos frutos, com tela (média dos 3 níveis de sombreamento) e sem tela, nos diferentes anos, para as cvs. Gala e Fuji. Fraiburgo-SC, 2000.

\begin{tabular}{|c|c|c|c|c|c|c|c|c|c|c|}
\hline & \multicolumn{2}{|c|}{$95 / 96$} & \multicolumn{2}{|c|}{$96 / 97$} & \multicolumn{2}{|c|}{$97 / 98$} & \multicolumn{2}{|c|}{ 98/99 } & \multicolumn{2}{|c|}{$99 / 00$} \\
\hline & $\begin{array}{l}\text { sem } \\
\text { tela }\end{array}$ & $\begin{array}{l}\text { com } \\
\text { tela }\end{array}$ & $\begin{array}{l}\text { sem } \\
\text { tela }\end{array}$ & $\begin{array}{l}\text { com } \\
\text { tela }\end{array}$ & $\begin{array}{l}\text { sem } \\
\text { tela }\end{array}$ & $\begin{array}{l}\text { com } \\
\text { tela }\end{array}$ & $\begin{array}{l}\text { sem } \\
\text { tela }\end{array}$ & $\begin{array}{l}\text { com } \\
\text { tela }\end{array}$ & $\begin{array}{l}\text { sem } \\
\text { tela }\end{array}$ & $\begin{array}{l}\text { com } \\
\text { tela }\end{array}$ \\
\hline $\begin{array}{l}\text { Gala } \\
\text { nal }\end{array}$ & 57,2 & 45,6 & 46,6 & 32,4 & 42,7 & 31.0 & 64.1 & 52.8 & 63.5 & 52.7 \\
\hline Diferença & \multicolumn{2}{|c|}{11,6} & \multicolumn{2}{|c|}{14,2} & \multicolumn{2}{|c|}{11,7} & \multicolumn{2}{|c|}{11,3} & \multicolumn{2}{|c|}{10,8} \\
\hline Fuji & 42,5 & 35,3 & 31,4 & 28,6 & 41,6 & 36.4 & -- & -- & -- & -- \\
\hline Diferença & \multicolumn{2}{|c|}{7,2} & \multicolumn{2}{|c|}{2,8} & \multicolumn{2}{|c|}{5,2} & \multicolumn{2}{|c|}{-- } & \multicolumn{2}{|c|}{-- } \\
\hline
\end{tabular}

A resposta desta variável é semelhante à observada na França, onde houve redução da coloração de 5 a $25 \%$, em média, variando de cultivar para cultivar e também de ano para ano (Garnaud, J. C. 1997; La Morinière, 2000). Em vista disso, Legros (1997) recomenda não utilizar tela preta em variedades bicolores, o que é o caso das cultivares Gala e Fuji.

As variações que ocorrem de ano para ano, devido às condições climáticas, e entre os níveis de sombreamento, podem ser melhor observadas na Figura 1, onde os frutos foram separados por classes de coloração, principalmente quando se observa a distribuição por classe do ano 98/99 e 99/2000, considerado bom para o desenvolvimento de cor e dos anos 96/97 e 97/98, considerados ruins.

Em termos de russeting, ocorreu uma frequência menor de frutos com grau 0 (ausência de russeting) nas plantas sem tela e uma freqüência menor de frutos com graus 2 e 3 (russeting fora da cavidade peduncular) nas plantas protegidas pela tela, não ocorrendo diferenças entre os ní- veis de sombreamento (Figura 1). Esta redução da incidência do russeting nas plantas sob tela explica-se pela diminuição da radiação solar que é um dos fatores de desenvolvimento do russeting.
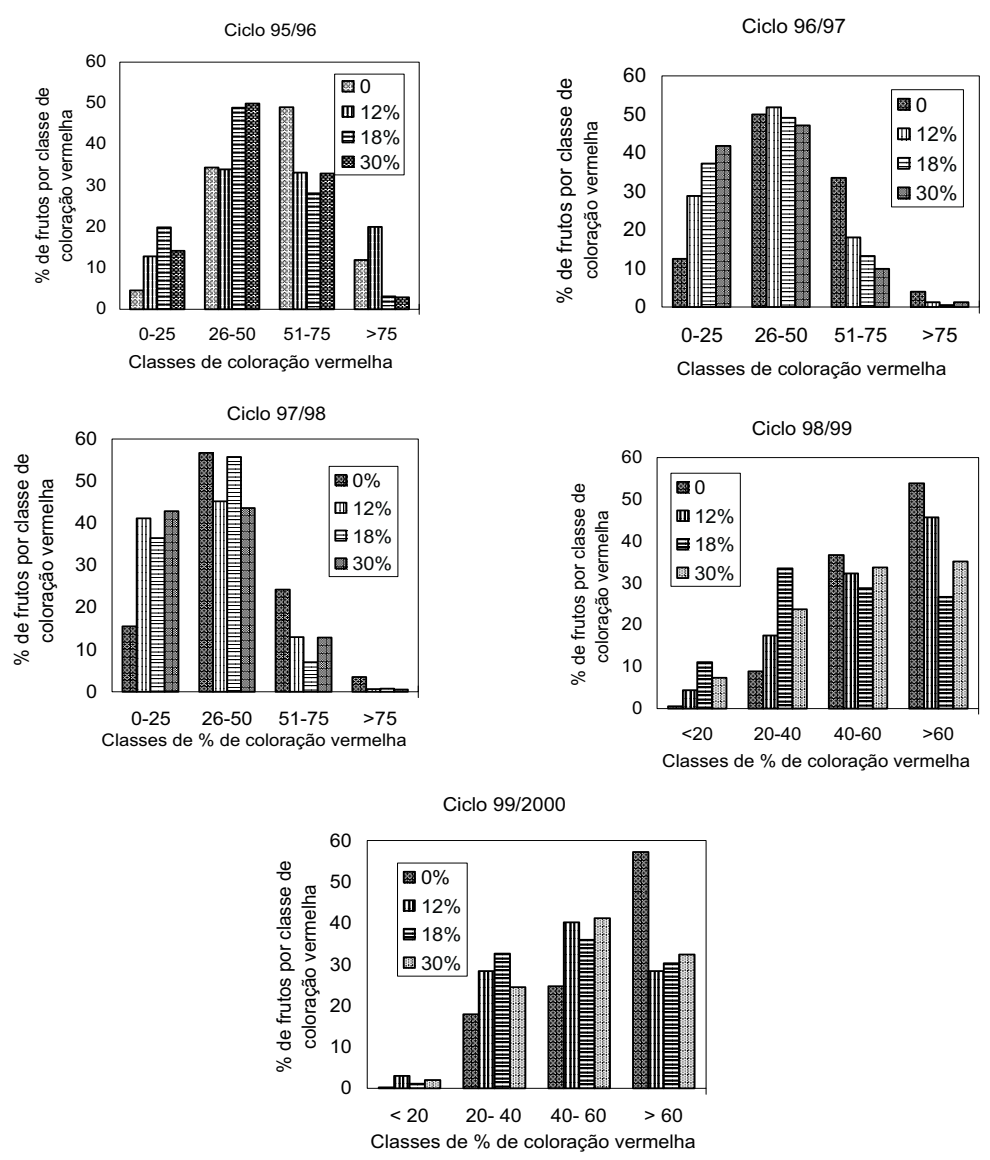

FIGURA 1 - Efeito do sombreamento sobre a coloração dos frutos na cv. Gala durante o período de 1997 a 2000 em Fraiburgo-SC.

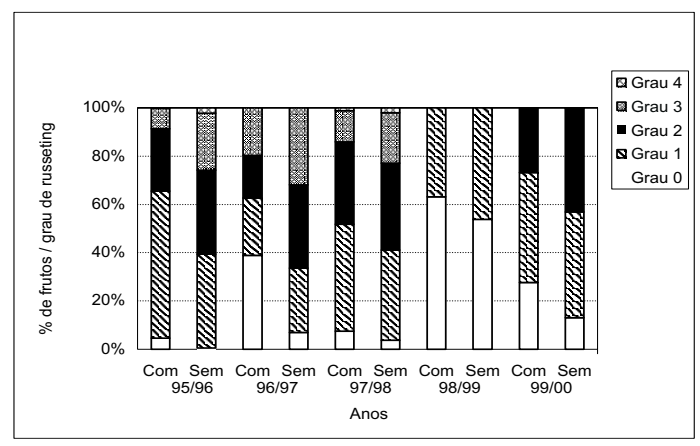

FIGURA 2 - Efeito da tela antigranizo sobre a ocorrência de russeting, grau 0 a 4, na cv. Gala, nos cinco anos, em Fraiburgo-SC.

Em anos com condições de alta umidade relativa favorável ao desenvolvimento da doença mancha de glomerela, a mesma poderá ser agravada nas plantas sob tela, devido à manutenção da umidade foliar por um período maior (Tabela 3), resultado da redução da radiação solar e da velocidade do vento.

As plantas sob a tela apresentaram menos gemas floríferas do que as plantas sem tela. Do mesmo modo, a porcentagem de gemas floríferas com frutos foi inferior nas plantas sob a tela (Tabela 4). Isto pode indicar, no primeiro caso, uma redução da diferenciação floral provocada pelo efeito de sombreamento da tela, e, no segundo caso, algum problema de polinização, podendo também estar relacionada à produção de gemas floríferas mais fracas, o que dificultaria a fecundação e a menor atividade das abelhas.

Quanto à influência da tela sobre a atividade das abelhas na polinização, observa-se, na Tabela 5, que o número de abelhas/planta/ minuto apresentou tendência a ser menor nas plantas sob tela, levando a crer que a presença da tela possa ser um empecilho à atividade das abelhas, comprometendo deste modo a polinização. 
TABELA 3 - Percentagem de frutos com mancha de glomerela (colletroticum sp.) - Fraiburgo-SC, 2000.

\begin{tabular}{cccc}
\hline \multirow{2}{*}{$\begin{array}{c}\text { SOMBREAMENTO } \\
\%\end{array}$} & \multicolumn{3}{c}{ \% DE FRUTOS COM GLOMERELLA } \\
\cline { 2 - 4 } & $96 / 97^{*}$ & $97 / 98$ & $98 / 99$ \\
\hline 0 & $0,37 \quad c$ & 10,5 & 0,7 \\
12 & $4,83 \mathrm{ab}$ & 26,2 & 2,0 \\
18 & $8,32 \mathrm{a}$ & 21,7 & 2,5 \\
30 & 2,86 bc & 18,4 & 2,6 \\
\hline
\end{tabular}

* Médias seguidas da mesma letra não diferem entre si, pelo teste de Duncan, a $5 \%$ de probabilidade.

TABELA 4 - Porcentagem de gemas floríferas totais e gemas floríferas com frutos na cv. Gala, ciclo 99/00 - Fraiburgo-SC.

$\begin{array}{ccc}\hline \mathbf{0} & \text { Gemas com flor }^{*} & \text { Gemas com frutos* }^{*} \\$\cline { 2 - 3 } $\left.\mathbf{1 2} & 64,0 \mathrm{a} & 49,8 \mathrm{a} \\ \mathbf{1 8} & 46,4 \mathrm{ab} & 30,4 \mathrm{~b} \\ \mathbf{3 0} & 36,9 \mathrm{~b} & 25,2 \mathrm{~b} \\ & 59,8 \mathrm{a} & 36,8 \mathrm{~b}\end{array}\right\} 30,8$

* Médias seguidas da mesma letra não diferem entre si, pelo teste de Duncan, a $5 \%$ de probabilidade.

TABELA 5 - Efeito da tela antigranizo sobre a atividade das abelhas na época de polinização Fraiburgo-SC.

1) Gala

\begin{tabular}{ccccc}
\hline Data & Horário & Sob a Tela & Fora da Tela \\
\cline { 3 - 5 } & & & Número de abelhas/planta/minuto \\
\hline $23-09$ & $13 \mathrm{~h} 30$ & $14 \mathrm{~h} 45$ & 3,40 & 4,10 \\
$27-09$ & $9 \mathrm{~h} 55$ & $11 \mathrm{~h} 02$ & 4,10 & 4,60 \\
\hline
\end{tabular}

2) Fuji

\begin{tabular}{ccccc}
\hline Data & Horário & Sob a Tela & Fora da Tela \\
\cline { 3 - 5 } & & & Número de abelhas/planta/minuto \\
\hline $21-09$ & $13 \mathrm{~h} 20$ & $14 \mathrm{~h} 46$ & 13,40 & 14,80 \\
$22-09$ & $11 \mathrm{~h} 09$ & $12 \mathrm{~h} 02$ & 5,25 & 5,16 \\
$23-09$ & $13 \mathrm{~h} 15$ & $14 \mathrm{~h} 05$ & 5,30 & 7,08 \\
$24-09$ & $15 \mathrm{~h} 05$ & $16 \mathrm{~h} 06$ & 3,30 & 5,00 \\
\hline
\end{tabular}

A eficiência da proteção da tela ao granizo é evidenciada, podendo as influências sobre a cultura da maçã serem superadas através do uso de clones de Gala e Fuji com coloração mais intensa e com o uso de telas com menor percentual de sombreamento (La Morinière, 2000), ou ainda com telas brancas.

\section{CONCLUSÕES}

1 - A tela antigranizo é eficiente para a proteção dos frutos contra danos provocados pela ocorrência de granizo.

2 - A cor vermelha é a variável que sofre maior influência (redução) do sombreamento provocado pela tela.

3 - A redução da coloração pelo sombreamento provocado pela tela é mais intenso na cv. Gala do que na cv. Fuji.

4 - Os efeitos do sombreamento sobre a produção variaram de ano para ano, conforme as condições climáticas.

5 - O russeting foi reduzido com a utilização da tela antigranizo.

6 - Na cv. Gala, há uma maior incidência de Colletotricum (mancha de glomerela) na área com proteção de tela.

7 - Telas antigranizo, com níveis de sombreamento inferiores a 12\%, são aconselháveis para reduzir os efeitos negativos na coloração dos frutos.

\section{REFERÊNCIAS BIBLIOGRÁFICAS}

ABPM - Associação Brasileira dos Produtores de Maça. Informação Pessoal. 1995.

CORINO, L. L’impiego delle reti antigrandine nella viticoltura. Convengo nazionale sul tema studio sui problemi relativi alla difesa della grandine, Asti, p.12-13, 1980.

GRANAUD, J.C. Les filets para grêle dans les verges/Anti-hail nets in fruit orchards. Plasticulture, n.113, p. 33-42, 1997.

LA MORINIÈRE, STATION D'ETUDES ET D'EXPERIMENTATIONS FRUTIÈRE NORD-LEGROS, N. Les filets antigrele: Etude de sysnthese. Le fruit belge, n. 467, p. 69-73, 1997.

LOIRE. Etudes \& Resultats, 1998-1999. ST Epain, p. 84-87.

MOTA, F.S. Meteorologia agrícola. São Paulo: Livraria Nobel, 1981, 376 p.

RAGAZZINI, D. VERONESI, G. Grandine: dalla conoscenza Del fenômeno l'efficacia della difesa. Genio rurale, v. 43, n. 5, p., 1980. V. XLIII, $\mathrm{n}^{\circ} 5,1980$.

ROSINI, E.; VENTO, D. La difesa antigrandine: il método soviético. L I Itália Agrícola. v. 113, n. 5, p. , 1976.

VENTO, D. La difesa attiva contro la grandine. Bologna: Edagricole Via Emilia Levante 31, 1976. p. 1-47. 